\title{
The influence of XBRL to audit and countermeasure research
}

\author{
Yuanqing Mao, Liucheng Zhang \\ School of Accountancy, Harbin University of Commerce, Harbin 150028, China
}

Keywords: XBRL; Audit; Influence; advice.

\begin{abstract}
The extensible business reporting language (XBRL) to the advent of audit work to bring convenient at the same time, also brought unprecedented problems and challenges to the audit work. This article first to the XBRL application in audit work situation briefly, and then XBRL influence on all aspects of the audit work is analyzed, finally put forward some prospects.
\end{abstract}

\section{The advantages of XBRL analysis}

The meaning of XBRL. XBRL is based on Internet, cross-platform manipulation, it is mainly used for financial reporting, disclosure and use of a computer language to write, with this to achieve data integration and maximize the use of accounting information output, data sharing, the combination of the international accounting standards and computer language, for unstructured data, especially the latest financial information exchange accepted standards and technologies. Experience to specific identification and classification of combined data, can be directly for the user or other software reads and further processing, to achieve an entry, use several times.

The advantages of XBRL. XBRL advantages we see, not only has brought the technology change, brought unprecedented changes to the audit work, for the whole accounting system has brought unprecedented innovation. We can understand its advantage in several ways. XBRL is in order to achieve the following objectives: reduce the cost of information exchange, improve the availability of information, the data in the network is effective. At the same time, due to reduced the conversion of accounting information of different report format and repeat entry, greatly improving the investors or data users use of the opportunities and efficiency of financial information. (1) the XBRL is a standard form, which can be used to write, send out a variety of different forms of financial information. By using XBRL can make the use of the message is more convenient, transmitted to manipulate XBRL financial report and related supply chain system for the welfare of the inevitable. (2) to provide a more accurate financial reports, to improve the user more confidence and information relevance. (3) reduced cost of data collection, data transfer and exchange efficiency. (4) secondary data ik more calls, quickly and easily read and analyze the data. (5) to make financial data have more broad comparability. (6) increased observational and maintainability data at a later date. (7) to adapt to the change of the request of the system of accounting standards. From what has been discussed above, we can find that the advantages of XBRL mainly embodied in the accounting information provided by users of accounting information by using XBRL form, get the financial statements of the electron transfer from the Internet.

\section{XBRL influence on audit.}

After fully using XBRL, earth-shaking changes have taken place in the audit work, working content, working form, working difficulty level has a huge change.

XBRL make auditing more comprehensive. The difference between the authentication function and emerging certification service. Announcement "authentication business standard according to the NO. 1" (ssae-16 report NO. 1) : the definition of "verification service is a kind of contract, in this convention, practitioners or promise to publish a written information, to express the reliability of the determination of the other party responsibility written conclusion." Financial statements auditing standards is performed by the auditor independence, auditors usually directly of opinions on the financial statements. The concrete is shown in figure 1. Certification service field is not set in stone, 
not artificial. It will not limit there will be opportunities in the future. Certification service will be improved to the content of the many aspects of information to help decision makers to better decisions.

XBRL promotes the innovation of audit procedures. Because the XBRL for the particularity of the audit requirements, called for an unprecedented change the entire audit program, using high and new science and technology greatly enhance the efficiency of the audit and the ability to process data automatically. Traditional forms of audit is audit the accounting content, namely tracking history data, retrieve the auditees in the past a certain point in time the financial position, operating results and cash flow. XBRL technology to promote the use makes real-time accounting system are successful implementation, the financial position of the need to audit on the auditees for continuous forensic investigation, namely the continuous auditing. As XBRL and enterprise business activities, information users can anytime, anywhere access to enterprise's accounting information from the Internet and understand the financial situation. In a real-time billing system, most of the financial information and audit evidence standard can only be acquired in a spreadsheet, and real-time online data processing to make a lot of business make manual document cannot leave the original data. XBRL is a transformation, but it can not change the existing accounting standard and accounting elements, he just put these electronic accounting elements, and in all kinds of accounting standards, accounting elements, accounting to build a bridge between. By figure 2 we can find that the XBRL, we will completely get rid of the long disturb our accounting data more diversification, standard gap, difficult to make the data collection.

XBRL promoted the audit practice mode of network. Due to the different regions or industries, information carrier is in a state of highly concentrated, thus greatly improve the use of the Internet, businesses generally implements comprehensive business network. Enterprise management system through network management restructuring at the same time, make the accounting data in electronic situation around in the Internet for information users in use at any time, has realized the long-distance real-time transmission of the message. Enterprise accounting information system further integrates network, many large and medium-sized enterprises can be directly through the network to disclose financial information. However, online data processing and complex audit procedures will greatly increase the difficulty of the audit work, especially when the information system provides data interface and the function is not accord with a standard system software package, they will become extremely complicated, thanks in large part to the CFO and use financial software provided resistance certified public accountants. Above the XBRL can effectively solve the complicated problem, its effective unified network format and data definition, relevant accounting data can be effectively used the exchange between different operating systems, database, software. XBRL application perfectly solves the problem in the operation of the network financial report and packages, including certified public accountant, chief financial officer and the information users can timely access to information, thus, making use of network technology easy to audit.

XBRL affect audit personnel quality. For the auditor, the impact of the XBRL is various, first is to the information system and control even familiar with the IT technology. Although from a certain extent, the auditor can skilled grasp the accounting aspects of the computer program operation, but for the XBRL is completely not know, or don't know anything for the audit of the computer of XBRL authorities also failed to understand. This means that the auditors will be eliminated by age, XBRL will be comprehensive application in the enterprise. On the other hand, after the implementation of XBRL, information is seamless transfer between different departments, and between each system software can also better seamless docking, removes the auditor exists in the communication between different departments of bitter, it greatly improved the auditor independence, save the time of the audit, reduces the audit cost.

\section{Future XBRL environment audit mode: XARL}

XARL was originally put forward the purpose of network security is to ensure that the XML file format. XARL can provide a verification of XBRL documents, makes the XBRL files more complete 
and reliable. XARL XARL classification standard, the digital signature technology, the public key technology and the identity authentication technology can ensure the reliability of information network transmission process. Through XARL classification standard to tag XARL documents can prove that the auditor has to audit, information of the auditees XARL instance document itself contains special markers, such as the guarantee type digital signature, date of guarantee, auditor, system reliability verification, etc. As a result, users can easily learn that authentication type, guarantee covers the period during which the and so on. So the final largely reduced doubts about the safety of accounting information reliability and information users.

\section{Acknowledgment}

This work is supported by National Social Science Fund Project 15BJY017.

\section{References}

[1] Fu Lijun. XBRL environment audit studies [J]. Friends of the accounting, 2011 (8) , pp. 14-15.

[2] Chen Geng. Based on XBRL financial report affect audit discussion [J]. Journal of management informationization in China, 2016 (9) , pp. 61-64.

[3] Niu lili. XBRL development and its influence on audit research [J]. Modern economic information, 2016 (11) , pp. 11-13

[4] Zhang Liucheng.Research of Innovation and Entrepreneurship Education in Harbin University of Commerce[J]. Social Science and Humanity, 2015(76) , pp. 130-133

[5] Zhang Liucheng.Application And Analysis Of Witkey Mode In Network Economy[J]. Advances in Social Science, Education and Humanities Research, 2015(31), pp. 178-181

[6] Zhang Liucheng.The Research and Innovation of Witkey Mode under the New Era[J]. Advances in Education Research, 2015 (11) , pp. 102-105.

[7] Zhang Liucheng.Research on the problems of the application of XBRL financial statement in small and medium sized enterprises[J]. Advances in Social Science, Education and Humanities Research, 2016（59）, pp. 1421-1424

[8] Zhang Liucheng.Application-oriented Institutes Innovation Thinking and Practice of Talent Training Mode[J]. Advances in Social Science, Education and Humanities Research, 2016 (59), pp. 1425-1429

[9] Zhang Liucheng.Analysis on the future development of cloud Education[J]. Advances in Social Science, Education and Humanities Research,2016（59）, pp. 1477-1480

[10] Zhang Liucheng.Research on the construction of education service platform based on Cloud Computing[J]. Advances in Social Science, Education and Humanities Research, 2016 (59) , pp. 1481-1484

[11] Gao Yuan, College students' innovative entrepreneurial training plan of project process management research and exploration [J], Journal of laboratory science, 2013 (6), pp. 71-74.

[12] Yang Weizhi, Using the simulation system to cultivate students ability of enterprise management [J], Journal of laboratory research and exploration, 2013, no. 4, pp. 11-13.

[13] Zhang Li,Applied talents cultivation of innovative thinking mode exploration [J], China's higher education, 2012, (19) , pp.12-13

[14] Chen Yinping, Yin Long, College students' innovative entrepreneurial training plan to carry out the practice and exploration, in Harbin university of commerce, for example [J], Journal of new economy, 2014,(15) , pp. 41-54.

[15] Si Songmen, Zhuang Yale, Thinking about college students' innovative entrepreneurial training program [J], Journal of heilongjiang education (higher education research and evaluation), 2014, (7) , pp. 31-33. 